\title{
The Structure and the Electrical Properties of $\mathrm{Pb}_{0.95} \mathbf{L a}_{0.05}\left[\mathrm{Zr}_{x} \mathbf{T i}_{(0.95-x)}\left(\mathrm{Mo}_{1 / 3}, \mathbf{I n}_{2 / 3}\right)_{0.05}\right]_{0.9875} \mathrm{O}_{3}$ Ferroelectric Ceramics
}

\author{
Malika Abba ${ }^{1}$, Ahmed Boutarfaia ${ }^{1,2^{*}}$ \\ ${ }^{1}$ Laboratoire de Chimie Appliquée, Université de Biskra, RP-Biskra, Algérie; ${ }^{2}$ Département de Sciences de la Matière, Université de \\ Ouargla, RP-Ouargla, Algérie. \\ Email: *aboutarfaia@yahoo.fr
}

Received January $30^{\text {th }}, 2011$; revised March $9^{\text {th }}, 2011$; accepted May $31^{\text {st }}, 2011$.

\begin{abstract}
The structural, the dielectric, and the piezoelectric properties of new ferroelectric

$\mathrm{Pb}_{0.95} \mathrm{La}_{0.05}\left[\mathrm{Zr}_{x} \mathrm{Ti}_{(0.95-x)}\left(\mathrm{Mo}_{1 / 3}, \mathrm{In}_{2 / 3}\right)_{0.05}\right]_{0.9875} \mathrm{O}_{3}(0.46 \leq x \leq 0.55)$ ceramics have been investigated. All the samples were being sintered at a temperature ranging from 1000 to $1180^{\circ} \mathrm{C}$ after being compacted in circular discs. The detailed structural and ferroelectric properties were carried out for sintered specimens. The results of X-ray diffraction showed that all the ceramics specimens have a perovskite phase. The phase structure of

$\mathrm{Pb}_{0.95} \mathrm{La}_{0.05}\left[\mathrm{Zr}_{x} \mathrm{Ti}_{(0.95-x)}\left(\mathrm{Mo}_{1 / 3}, \mathrm{In}_{2 / 3}\right)_{0.05}\right]_{0.9875} \mathrm{O}_{3}$ ceramics was transformed from the tetragonal to the rhombohedral, with an increase in the ratio of $\mathrm{Zr} / \mathrm{Ti}$ in system. In the present system the MPB that coexists with the tetragonal and rhombohedral phases is a narrow composition region of $x=0.50-0.51$. The scanning Electron Microscopy (SEM) showed an increase of the mean grain size when the sintering temperature was increased. The dielectric constant $\varepsilon$ and the coupling factor $K_{p}$ reached the maximum values, while the mechanical quality factor $Q_{m}$ and the loss tangent reached the lowest values when $x=0.50$. For the composition where $x=0.50$, these properties include $\varepsilon=5414$ (at the Curie temperature), $\operatorname{tang} \delta=0.039, K_{p}=0.67, Q_{m}=20$ and a Curie temperature of $335^{\circ} \mathrm{C}$.
\end{abstract}

Keywords: MPB, Sintering, Piezoelectric, Dielectric, Zr/Ti Ratio, Ceramic

\section{Introduction}

The lead zirconate titanate materials $\mathrm{Pb}\left(\mathrm{Zr}_{x} \mathrm{Ti}_{1-x}\right) \mathrm{O}_{3}(\mathrm{PZT})$ of a perovskite-type represented by the formula $\mathrm{ABO}_{3}$, have been extensively used for the piezoelectric applications such as capacitors, sensors, actuators and other high piezoelectric devices. In the PZT materials, the dielectric, the ferroelectric, and the electromechanical characteristics have been modified when several substitutions were being done on the A- or/and B-sites, and also by varying the ratio of $\mathrm{Zr} / \mathrm{Ti}$ [1-6]. Since the discovery of the behavior of the relaxor in $\mathrm{Pb}\left(\mathrm{Mg}_{1 / 3}, \mathrm{Nb}_{2 / 3}\right) \mathrm{O}_{3}$ [7], $\mathrm{Pb}\left(\mathrm{Zn}_{1 / 3}, \mathrm{Nb}_{2 / 3}\right) \mathrm{O}_{3}$ [8], and $\mathrm{Pb}\left(\mathrm{Ni}_{1 / 3}, \mathrm{Nb}_{2 / 3}\right) \mathrm{O}_{3}$ [9], the studies of the ferroelectrics of the relaxor with $\mathrm{Pb}\left(\mathrm{B}_{1 / 3}\right.$, $\left.\mathrm{B}{ }_{2 / 3}\right) \mathrm{O}_{3}$-type perovskites have attracted much attention because of their excellent dielectric and electromechanical properties. In a conventionally prepared PZT ceramics with compositions near the morpho-tropic phase boundary (MPB), the tetragonal, and the rhombohedral phases always coexist [9]. The width and the properties of the coexistence region are associated with the occurrence of the compositional fluctuation of $\mathrm{Ti}^{4+}$ and $\mathrm{Zr}^{4+}$ ions in the PZT materials [10]. The compositional fluctuation, which is due to a non-uniform distribution of Titanium and Zirconium ions, leads to a broad variation in the dielectric constant accompanied with a Zirconium concentration in the MPB region [11]. The width of this coexistence region and the structure of the PZT ceramics were greatly affected by the firing time and temperature [12]. The selection of dopants or substitutions to tailor some physical properties of PZT was based on many factors which are the following: 1) charge neutrality, 2) tolerance factors, 3) ionic radius, and 4) solubility/ miscibility. The substitution of lanthanides and the different doped material at $\mathrm{Pb}$-sites and Zirconium at the Ti-sites with a different ratio of $\mathrm{Zr} / \mathrm{Ti}$ have produced many solid solutions with interesting properties for wide industrial applications. The understanding of the relationships between the variations in the physical properties 
and the phase coexistence with a composition is very important because, first, they produce a great influence on the characteristics of the PZT ceramics; and, second, they stabilize the temperature and the time in the region of the phase transition between the tetragonal and the rhombohedral phases.

In this study,

$\mathrm{Pb}_{0.95} \mathrm{La}_{0.05}\left[\mathrm{Zr}_{x} \mathrm{Ti}_{(0.95-x)}\left(\mathrm{Mo}_{1 / 3}, \mathrm{In}_{2 / 3}\right)_{0.05}\right]_{0.9875} \mathrm{O}_{3}$ piezoelectric ceramics were investigated near the MPB by varying the ratio of $\mathrm{Zr} / \mathrm{Ti}$. The purpose of this work was to study the phase structure, the dielectric, and the piezoelectric properties of these ceramics near the MPB in detail.

\section{Experimental Procedure}

The polycrystalline samples with a general compositional formula $\mathrm{Pb}_{1-z} \mathrm{La}_{z}\left[\mathrm{Zr}_{x} \mathrm{Ti}_{y}\left(\mathrm{Mo}_{1 / 3}, \mathrm{In}_{2 / 3}\right)_{1-(x+y)}\right]_{1-z / 4} \mathrm{O}_{3}$ with $z=0.05,(x+y)=0.95$ and $0.46 \leq x \leq 0.55$ were being prepared by a conventional dry ceramic method to form the solid solution of a composition that follows: $\mathrm{Pb}_{0.95} \mathrm{La}_{0.05}\left[\mathrm{Zr}_{x} \mathrm{Ti}_{(0.95-x)}\left(\mathrm{Mo}_{1 / 3}, \mathrm{In}_{2 / 3}\right)_{0.05}\right]_{0.9875} \mathrm{O}_{3}$. The reagent grade oxide of $\mathrm{PbO}, \mathrm{ZrO}_{2}, \mathrm{TiO}_{2}, \mathrm{La}_{2} \mathrm{O}_{3}, \mathrm{MoO}_{3}$ and $\mathrm{In}_{2} \mathrm{O}_{3}$ were used as starting materials in a stoichiometric ratio. The powders were, first, ball-milled for twelve hours; and, then, calcined at $800^{\circ} \mathrm{C}$ for two hours at the following heating and cooling rates: $2^{\circ} \mathrm{C} / \mathrm{min}$. After calcination, the mixture was, first, ball-milled for twentyfour hours; and then, dried and granulated with PVA as a binder. After drying, the powders were pressed into discs of a diameter of thirteen millimeters and of a thickness of about one millimeter. The compacted discs were being sintered at a temperature ranging from $1000^{\circ} \mathrm{C}-1180^{\circ} \mathrm{C}$ for two hours in air. To prevent $\mathrm{PbO}$ volatilization from the pellets, a $\mathrm{PbO}$ atmosphere was controlled with a bed of $\mathrm{PbZrO}_{3}$ powder placed in the vicinity of the pellets.

The X-ray diffraction (XRD, Simens D500) was used to determine the crystalline phases present in the powder. The compositions of PZT phases were identified by the analysis of the peaks $[(002) \mathrm{T},(200) \mathrm{R},(200) \mathrm{T}]$ in the twenty range $43^{\circ}-46^{\circ}$. The $\mathrm{Cu} \mathrm{K} \alpha$ radiation with a step of $0.01^{\circ}$ was used. The bulk densities of the sintered ceramics were being measured by the Archimedes method. The micrographs of the fractured samples were taken on a JEOL scanning electron microscope. The average grain size of the samples was determined from the micrographs by the linear intercept technique. To investigate the electrical properties, the electrodes were made by applying a silver paste on the two major faces of the sintered disks followed by a heat treatment at $750^{\circ} \mathrm{C}$ for thirty minutes. The dielectric constant $\varepsilon$ was calculated from the capacitance at a frequency of one $\mathrm{kHz}$. It was measured at temperatures ranging from $25^{\circ} \mathrm{C}$ to $400^{\circ} \mathrm{C}$ with a heating rate of one ${ }^{\circ} \mathrm{C}$ /minute by using an impedance analyzer (HP 4192A, Hewlett-Packard). The piezoelectric samples were, first, being poled in a silicone oil bath at $120^{\circ} \mathrm{C}$ by applying a d.c. field of thirty $\mathrm{kV} / \mathrm{cm}$ for thirty minutes; and, then, were being cooled under the same electric field.

They were aged for twenty-four hours before testing. The electromechanical coupling factor $K_{p}$, along with the mechanical quality factor $Q_{m}$ were determined by the resonance and anti-resonance technique from the equations [13]:

$$
\begin{gathered}
K_{p}=\left[\frac{2.51 \times\left(f_{a}^{2}-f_{r}^{2}\right)}{2 f_{a}^{2}}\right]^{1 / 2} \\
Q_{m}=\left[4 \pi \times\left(f_{a}-f_{r}\right) \times R C\right]^{-1}
\end{gathered}
$$

where:

$$
\begin{aligned}
& f_{a}: \text { anti-resonant frequency }(\mathrm{Hz}) \\
& f_{r}: \text { resonant frequency }(\mathrm{Hz}) \\
& R: \text { resonant resistance }(\mathrm{ohms}) \\
& C: \text { capacity (faraday) }
\end{aligned}
$$

\section{Results and Discussion}

The analysis of the phase was performed from the XRD (at a room temperature) patterns over a range of $2 \theta=43^{\circ}$ to $46^{\circ}$, where the tetragonal phase displays two peaks, $(002)_{T}$ and $(200)_{T}$, and the rhombohedral phase displays one peak, $(200)_{R}$. There was a broad region where the two phases, the rhombohedral and the tetragonal, coexisted. This indicated a typical morpho-tropic phase behavior (MPB). The typical patterns of the X-ray diffraction of $\mathrm{Pb}_{0.95} \mathrm{La}_{0.05}\left[\mathrm{Zr}_{x} \mathrm{Ti}_{(0.95-x)}\left(\mathrm{Mo}_{1 / 3}, \mathrm{In}_{2 / 3}\right)_{0.05}\right]_{0.9875} \mathrm{O}_{3}$ compositions is shown in Figure 1. The samples obtained in this study are summarized in Table 1. At $1150^{\circ} \mathrm{C}$, a typical tetragonal phase was observed at a room temperature when $x_{T}>0.50$. The $(002)_{\mathrm{T}}$ and $(200)_{\mathrm{T}}$ peaks split into the $(200)_{\mathrm{R}}$ peak as the ratio of $\mathrm{Zr} / \mathrm{Ti}$ was increased. The rhombohedral phase can be obtained when $x_{R}<0.51$. A transition from the tetragonal to the rhombohedral phase was observed as the ratio of $\mathrm{Zr} / \mathrm{Ti}$ was increased. The Rhombohedral and the tetragonal phases coexisted at $x=0.50-0.51$, and demonstrated that the ceramic resided at the morpho-tropic phase boundary (MPB) [14]. The parameters of the lattice were, then, determined from the triplets (200) by using a non-linear least squares method [15]. The $a_{R}$-parameter of the rhombohedral phase and the $a_{T}$-parameter, $c_{T}$-parameter, and the tetragonality $\left(c_{T} / a_{T}\right)$ of the tetragonal phase of $\mathrm{Pb}_{0.95} \mathrm{La}_{0.05}\left[\mathrm{Zr}_{x}, \mathrm{Ti}_{(0.95-x)}\left(\mathrm{Mo}_{1 / 3}, \mathrm{In}_{2 / 3}\right)_{0.05}\right]_{0.9875} \mathrm{O}_{3}$ ceramics are plotted as a function of the ratio of $\mathrm{Zr} / \mathrm{Ti}$ in Figure 2. The results showed that the parameters of the lattice of the tetragonal phase changed when the ratio of $\mathrm{Zr} / \mathrm{Ti}$ was modified. While the value of the $a_{T}$ parameter increased, the one of $c_{T}$ parameter decreased, and the $a_{R}$ parameter of the rhombohedral phase increased along 
Table 1. Series of compositions and crystal structure.

\begin{tabular}{|c|c|c|c|c|}
\hline \multirow[b]{2}{*}{ Sample } & \multicolumn{4}{|c|}{ Crystal structure } \\
\hline & $1000^{\circ} \mathrm{C}$ & $1100^{\circ} \mathrm{C}$ & $1150^{\circ} \mathrm{C}$ & $1180^{\circ} \mathrm{C}$ \\
\hline $\mathrm{Pb}_{0.95} \mathrm{La}_{0.05}\left[\mathrm{Zr}_{0.46} \mathrm{Ti}_{0.49}\left(\mathrm{Mo}_{1 / 3}, \mathrm{In}_{2 / 3}\right)_{0.05}\right]_{0.9875} \mathrm{O}_{3}$ & $\mathrm{~T}$ & $\mathrm{~T}$ & - & - \\
\hline $\mathrm{Pb}_{0.95} \mathrm{La}_{0.05}\left[\mathrm{Zr}_{0.47} \mathrm{Ti}_{0.48}\left(\mathrm{Mo}_{1 / 3}, \mathrm{In}_{2 / 3}\right)_{0.05}\right]_{0.9875} \mathrm{O}_{3}$ & $\mathrm{~T}+\mathrm{R}$ & $\mathrm{T}$ & $\mathrm{T}$ & - \\
\hline $\mathrm{Pb}_{0.95} \mathrm{La}_{0.05}\left[\mathrm{Zr}_{0.49} \mathrm{Ti}_{0.46}\left(\mathrm{Mo}_{1 / 3}, \mathrm{In}_{2 / 3}\right)_{0.05}\right]_{0.9875} \mathrm{O}_{3}$ & $\mathrm{~T}+\mathrm{R}$ & $\mathrm{T}+\mathrm{R}$ & $\mathrm{T}$ & $\mathrm{T}$ \\
\hline $\mathrm{Pb}_{0.95} \mathrm{La}_{0.05}\left[\mathrm{Zr}_{0.50} \mathrm{Ti}_{0.45}\left(\mathrm{Mo}_{1 / 3}, \mathrm{In}_{2 / 3}\right)_{0.05}\right]_{0.9875} \mathrm{O}_{3}$ & $\mathrm{~T}+\mathrm{R}$ & $\mathrm{T}+\mathrm{R}$ & $\mathrm{T}+\mathrm{R}$ & $\mathrm{T}+\mathrm{R}$ \\
\hline $\mathrm{Pb}_{0.95} \mathrm{La}_{0.05}\left[\mathrm{Zr}_{0.51} \mathrm{Ti}_{0.44}\left(\mathrm{Mo}_{1 / 3}, \mathrm{In}_{2 / 3}\right)_{0.05}\right]_{0.9875} \mathrm{O}_{3}$ & $\mathrm{~T}+\mathrm{R}$ & $\mathrm{T}+\mathrm{R}$ & $\mathrm{T}+\mathrm{R}$ & $\mathrm{T}+\mathrm{R}$ \\
\hline $\mathrm{Pb}_{0.95} \mathrm{~L}_{0.05}\left[\mathrm{Zr}_{0.54} \mathrm{Ti}_{0.41}\left(\mathrm{Mo}_{1 / 3}, \mathrm{In}_{2 / 3}\right)_{0.05}\right]_{0.9875} \mathrm{O}_{3}$ & $\mathrm{~T}+\mathrm{R}$ & $\mathrm{T}+\mathrm{R}$ & $\mathrm{R}$ & - \\
\hline $\mathrm{Pb}_{0.95} \mathrm{La}_{0.05}\left[\mathrm{Zr}_{0.55} \mathrm{Ti}_{0.40}\left(\mathrm{Mo}_{1 / 3}, \mathrm{In}_{2 / 3}\right)_{0.05}\right]_{0.9875} \mathrm{O}_{3}$ & $\mathrm{R}$ & $\mathrm{R}$ & - & - \\
\hline
\end{tabular}

$\mathrm{T}=$ Tetragonal; $\mathrm{R}=$ Rhombohedral; $\mathrm{T}-\mathrm{R}=$ Tetragonal-Rhombohedral.

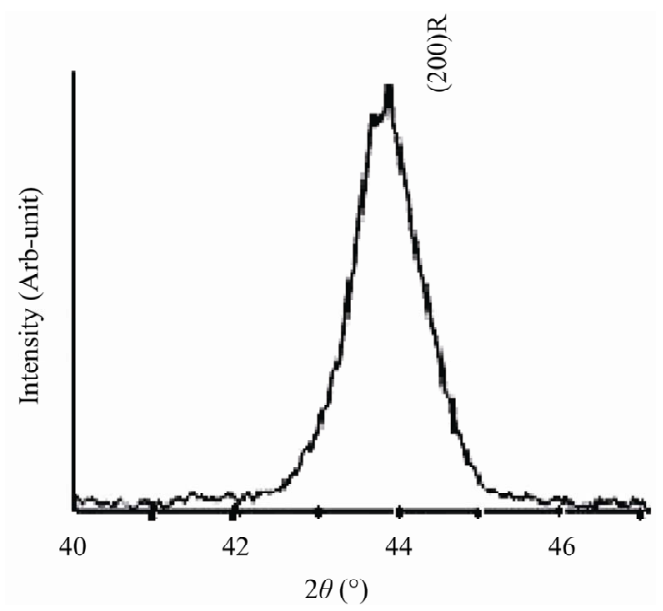

(a)

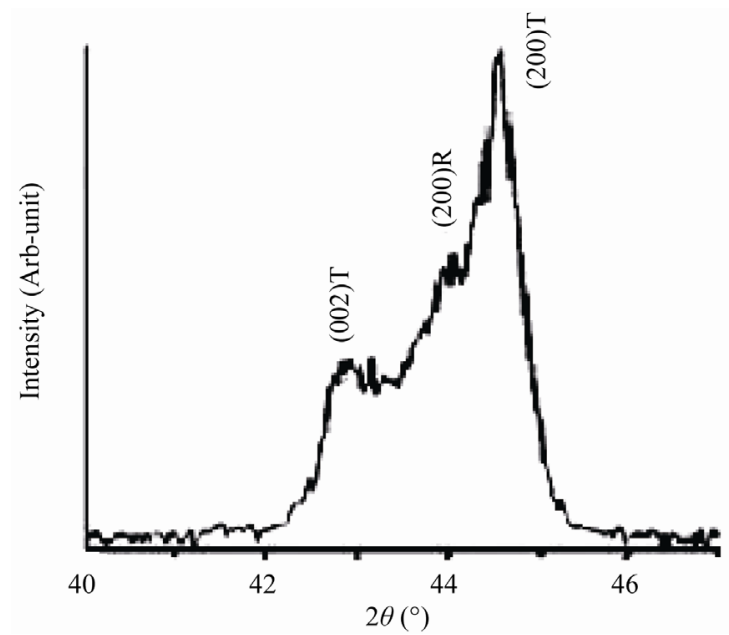

(c)

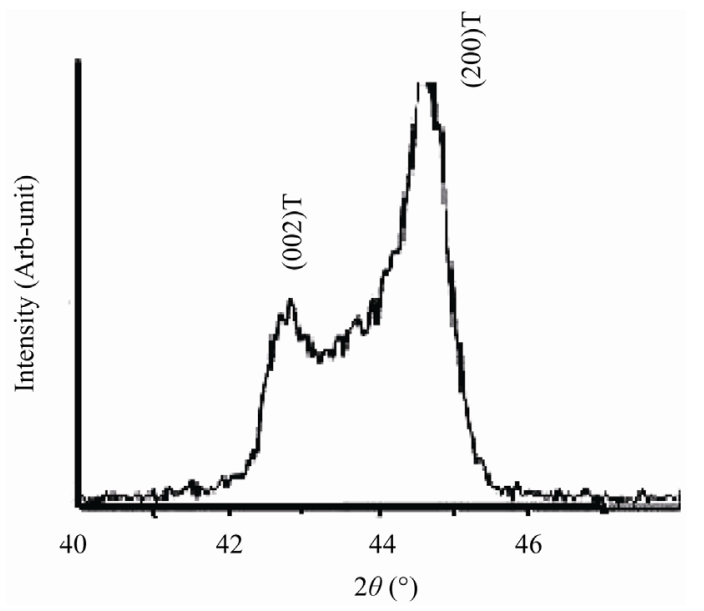

(b)

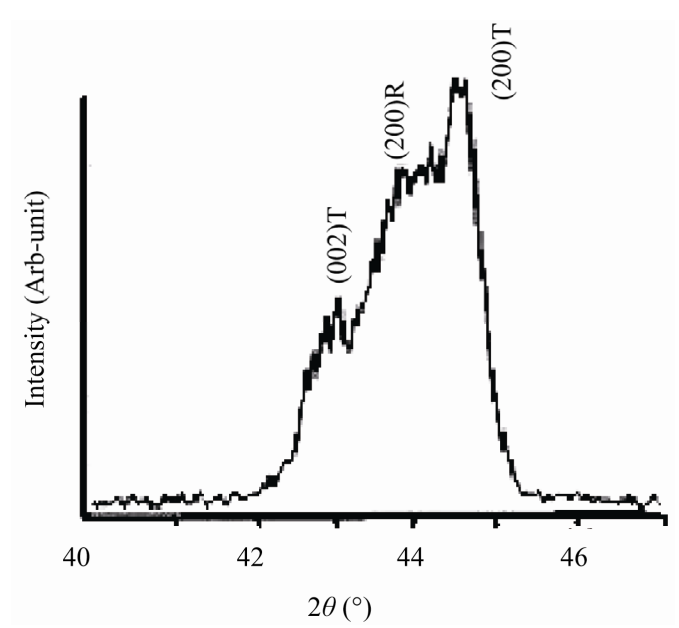

(d)

Figrue 1. XRD patterns of $\mathrm{Pb}_{0.95} \mathrm{La}_{0.05}\left[\mathrm{Zr}_{x} \mathrm{Ti}_{(0.95-x)}\left(\mathrm{Mo}_{1 / 3}, \mathrm{In}_{2 / 3}\right)_{0.05}\right]_{0.9875} \mathrm{O}_{3}$ ceramics sintered at $1150^{\circ} \mathrm{C}$ for $2 \mathrm{~h}$ : (a) $x=0.52$, (b) $x$ $=0.46$, (c) $x=0.50$ and (d) $x=0.51$.

with the sintering temperature in the coexistence region. The resulting values of the parameters of the lattice of the tetragonal phase showed that the $c_{T} / a_{T}$ axial ratio decreased as $a_{T}$ increased and $c_{T}$ decreased. The values of the parameters of the lattice were revealed to be practically the same as those previously studied $[16$, 17].

Figure 3 shows the SEM micrographs of $\mathrm{Pb}_{0.95} \mathrm{La}_{0.05}\left[\mathrm{Zr}_{0.50} \mathrm{Ti}_{0.45}\left(\mathrm{Mo}_{1 / 3}, \mathrm{In}_{2 / 3}\right)_{0.05}\right]_{0.9875} \mathrm{O}_{3}$ ceramics sintered at different temperatures. It can be observed 


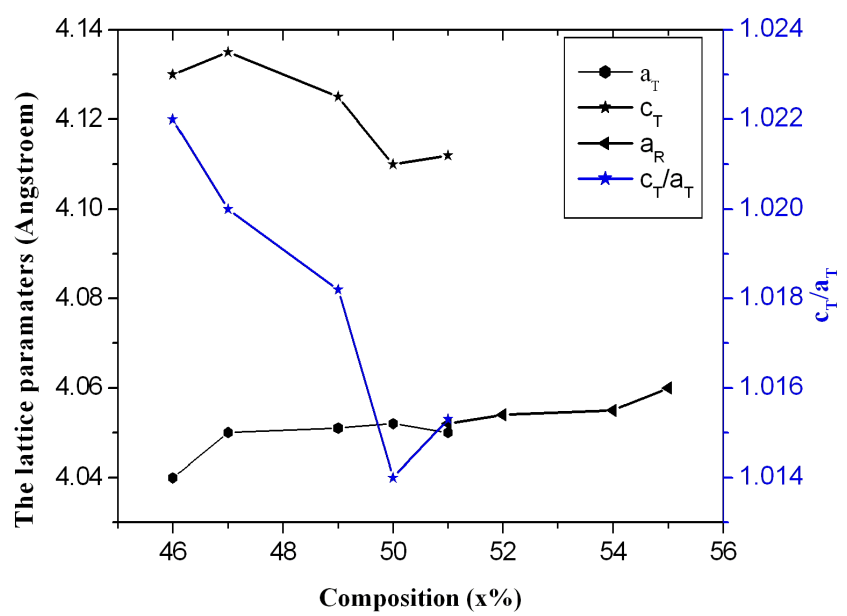

Figure 2. The parameters of the lattice of $\mathrm{Pb}_{0.95} \mathrm{La}_{0.05}\left[\mathrm{Zr}_{x} \mathrm{Ti}_{(0.95-x)}\left(\mathrm{Mo}_{1 / 3}, \mathrm{In}_{2 / 3}\right)_{0.05}\right]_{0.9875} \mathrm{O}_{3}$ ceramics as a function of composition ( for a sintering temperature about $1150^{\circ} \mathrm{C}$ ).
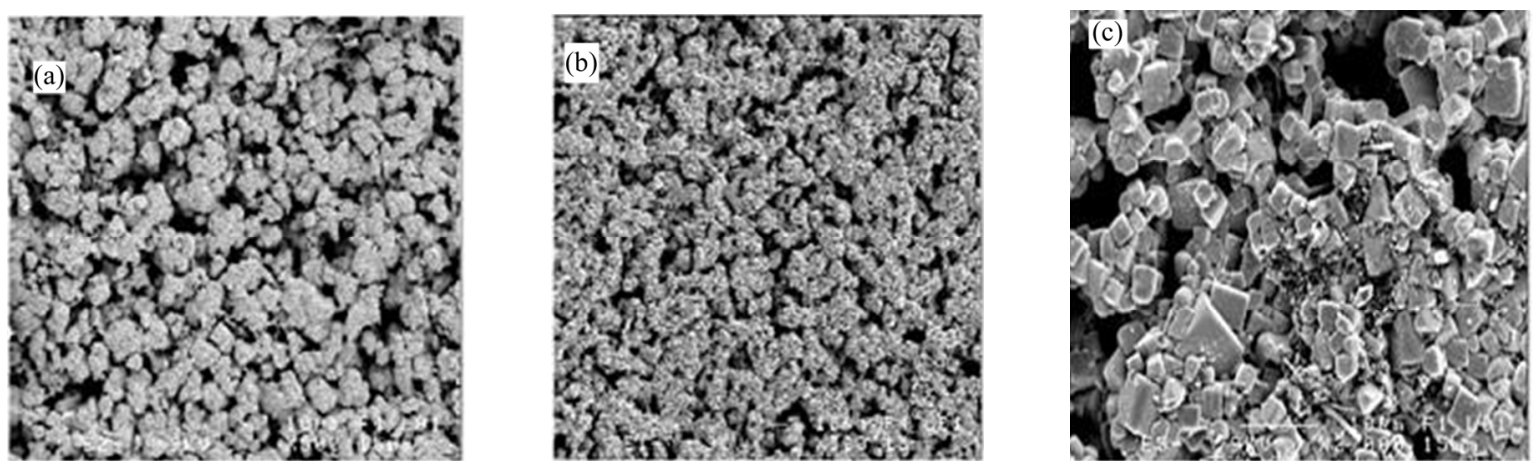

Figure 3. SEM micrographs for $\mathrm{Pb}_{0.95} \mathrm{La}_{0.05}\left[\mathrm{Zr}_{0.50} \mathrm{Ti}_{0.45}\left(\mathrm{Mo}_{1 / 3}, \mathrm{In}_{2 / 3}\right)_{0.05}\right]_{0.9875} \mathrm{O}_{3}$ ceramics sintered at (a)1000 ${ }^{\circ} \mathrm{C},(\mathrm{b}) 1100^{\circ} \mathrm{C}$ and (c) $1150^{\circ} \mathrm{C}$.

that many distinct pores exist on the surface of the $\mathrm{Pb}_{0.95} \mathrm{La}_{0.05}\left[\mathrm{Zr}_{0.50} \mathrm{Ti}_{0.45}\left(\mathrm{Mo}_{1 / 3}, \mathrm{In}_{2 / 3}\right)_{0.05}\right]_{0.9875} \mathrm{O}_{3}$ ceramics sintered at $1000^{\circ} \mathrm{C}$ and the average grain size is under 9 $\mu \mathrm{m}$. When the sintering temperature is increased, the pores can hardly be observed and the grain size is about 9 $\mu \mathrm{m}$. This indicates that a high sintering temperature promotes a grain growth process. The obtained images show a slight difference in the particle size and also give rise to the different phases, viz. the tetragonal, the rhombohedral, and the tetragonal-rhombohedral. In addition to the morphological modification of grains, different grain sizes could be noticed for these samples. In this way, the coexistence region of the tetragonal-rhombohedral phases was demonstrated.

The values of the room temperature of the dielectric constant $(\varepsilon)$ and the dissipation factor $(\tan \delta)$ at $1 \mathrm{kHz}$ for all samples are given in Figure 4. It can be seen that the $\varepsilon$ curve appears to be parabolic, and the values of $\varepsilon$ increase sharply from $46 / 49$ to $50 / 45$; and, also, large dielectric constants are obtained at the compositions of $50 / 45(\varepsilon=430$ at $1 \mathrm{kHz})$ and $51 / 44(\varepsilon=390$ at $1 \mathrm{kHz})$. It, then, follows a decreasing trend when the ratio of $\mathrm{Zr} / \mathrm{Ti}$ is increased further. The present results verify the conclusions about the dielectric constant peak in MPB. The increase in $\mathrm{Zr}$ content induces the microstructure transition of $\mathrm{Pb}_{0.95} \mathrm{La}_{0.05}\left[\mathrm{Zr}_{x} \mathrm{Ti}_{(0.95-x)}\left(\mathrm{Mo}_{1 / 3}, \mathrm{In}_{2 / 3}\right)_{0.05}\right]_{0.9875} \mathrm{O}_{3}$ from the rhombohedral to the tetragonal phase within the MPB region, as indicated by the above XRD investigations. The $\tan \delta$ shows an inverse trend and reaches the minimum value of $3.9 \%$ when $x=0.50$. Thus the compositions at 50/45 and 51/44 are at the center of the MPB.

Figure 5 reveals the dielectric constant $\varepsilon$ as a function of temperature for the

$\mathrm{Pb}_{0.95} \mathrm{La}_{0.05}\left[\mathrm{Zr}_{x} \mathrm{Ti}_{(0.95-x)}\left(\mathrm{Mo}_{1 / 3}, \mathrm{In}_{2 / 3}\right)_{0.05}\right]_{0.9875} \mathrm{O}_{3}$ ceramics $(x$ $=0.50$ and $x=0.51)$ sintered at $1150^{\circ} \mathrm{C}$, which were measured at a frequency of $1 \mathrm{kHz}$. As it might be known, two peaks are observed on the dielectric constant versus temperature curves in the measured temperature which ranges between $265^{\circ} \mathrm{C}$ and $330^{\circ} \mathrm{C}$ for a sample of a ceramic 50/45. The first dielectric peak corresponds to the transition temperature $T_{R-T}$, of the rhombohedral to the tetragonal phase, but the second peak, which results at a 


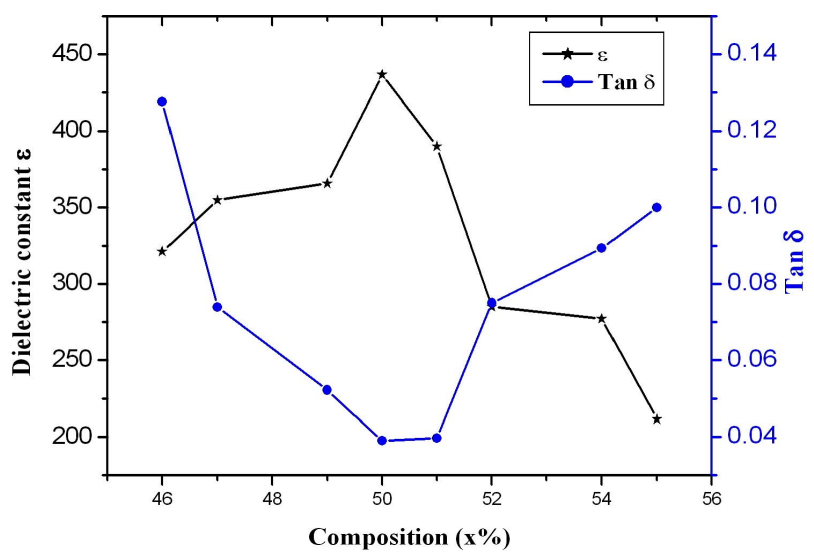

Figure 4.The dielectric constant $\varepsilon$ and the loss tangent (at room temperature, $1 \mathrm{KHz}$ ) for

$\mathrm{Pb}_{0.95} \mathrm{La}_{0.05}\left[\mathrm{Zr}_{x}, \mathrm{Ti}_{(0.95-x)}\left(\mathrm{Mo}_{1 / 3}, \mathrm{In}_{2 / 3}\right)_{0.05}\right]_{0.9875} \mathrm{O}_{3}$ ceramics as a function of composition.

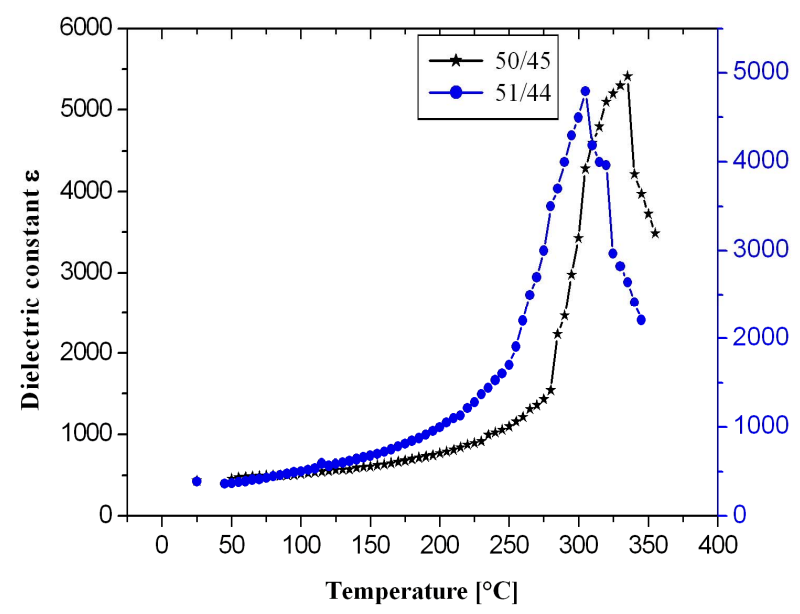

Figure 5. The dielectric constant $\varepsilon$ (at $1 \mathrm{KHz}$ ) for $\mathrm{Pb}_{0.95} \mathrm{La}_{0.05}\left[\mathrm{Zr}_{x} \mathrm{Ti}_{(0.95-x)}\left(\mathrm{Mo}_{1 / 3}, \mathrm{In}_{2 / 3}\right)_{0.05}\right]_{0.9875} \mathrm{O}_{3}$ ceramics as a function of temperature.

higher temperature, is the Curie temperature $T_{\mathrm{c}}$. The broadening in the transition phase is attributed to the structural disorder and the compositional fluctuation present in the arrangement of cation at A-site and B-site with lattice vacancies. This results in a microscopic heterogeneity in the composition and the distribution of different local Curie points [18].

Figure 6 shows the variation of the electromechanical coupling factor $K_{p}$ and the mechanical quality factor $Q_{m}$ for $\mathrm{Pb}_{0.95} \mathrm{La}_{0.05}\left[\mathrm{Zr}_{x} \mathrm{Ti}_{(0.95-x)}\left(\mathrm{Mo}_{1 / 3}, \mathrm{In}_{2 / 3}\right)_{0.05}\right]_{0.9875} \mathrm{O}_{3}$ ceramics. It is observed in Figure 6 that as the ratio of $\mathrm{Zr} / \mathrm{Ti}$ increases, the value of $\mathrm{kp}$ increases; and, subsequently, represents a peak of 0.67 at the ratio of $\mathrm{Zr} / \mathrm{Ti}$ of 50/45; but, when the ratio of $\mathrm{Zr} / \mathrm{Ti}$ is further increased, the value of $K_{p}$ decreases. $Q_{m}$ continues to decrease; and, finally, shows the minimum value when the ratio of

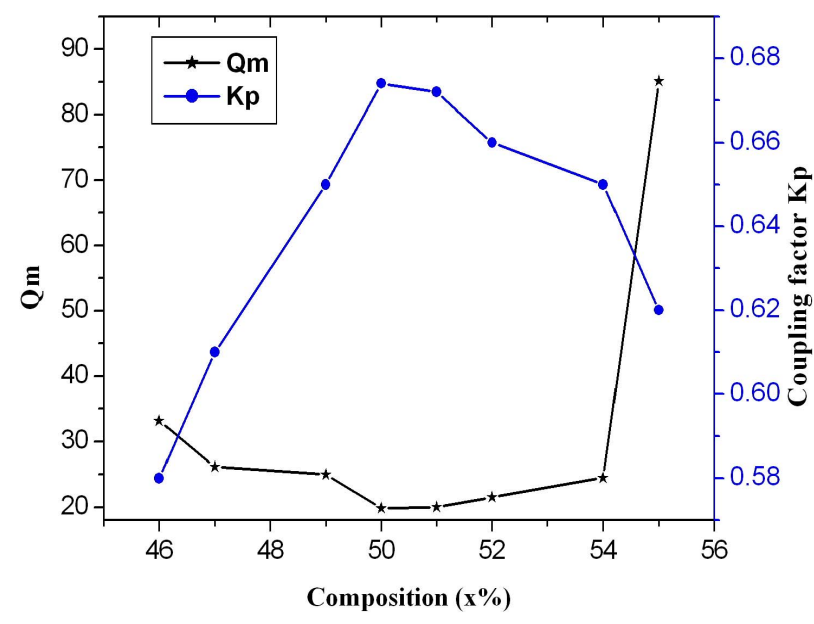

Figure 6. The Coupling factor $K_{p}$ and $Q_{m}$ for

$\mathrm{Pb}_{0.95} \mathrm{La}_{0.05}\left[\mathrm{Zr}_{\mathrm{x}} \mathrm{Ti}\left({ }_{0.95-x}\right)\left(\mathrm{Mo}_{1 / 3}, \mathrm{In}_{2 / 3}\right)_{0.05}\right]_{0.9875} \mathrm{O}_{3}$ ceramics sintered at $1150^{\circ} \mathrm{C}$ as a function of composition $(x)$.

$\mathrm{Zr} / \mathrm{Ti}$ is $50 / 45\left(Q_{m}=20\right)$. This is due to the fact that the structure of the phase of

$\mathrm{Pb}_{0.95} \mathrm{La}_{0.05}\left[\mathrm{Zr}_{x} \mathrm{Ti}_{(0.95-x)}\left(\mathrm{Mo}_{1 / 3}, \mathrm{In}_{2 / 3}\right)_{0.05}\right]_{0.9875} \mathrm{O}_{3} \quad$ ceramics changes, first, from the tetragonal phase to the coexistence of both the tetragonal and the rhombohedral phases; and, then, changes to a single rhombohedral phase when the ratio of $\mathrm{Zr} / \mathrm{Ti}$ is increased.

\section{Conclusions}

The aim of this study was to investigate the structure and the behavior of the electrical properties in

$\mathrm{Pb}_{0.95} \mathrm{La}_{0.05}\left[\mathrm{Zr}_{x} \mathrm{Ti}_{(0.95-x)}\left(\mathrm{Mo}_{1 / 3}, \mathrm{In}_{2 / 3}\right)_{0.05}\right]_{0.9875} \mathrm{O}_{3}$. The phases of the sintered samples were examined by X-ray diffractometry. The structure of the phase of the system was changed from the tetragonal to the rhombohedral as the ratio of $\mathrm{Zr} / \mathrm{Ti}$ was increased. The XRD results reveal that an MPB with the co-existence of the rhombohedral and the tetragonal for the ceramics lies in the range of $x=$ $0.50-0.51$. The parameters of the lattice: $a_{T}$ and $c_{T}$ of the tetragonal structure and $a_{R}$ of the rhombohedral structure were found to change when composition is modified. The $\mathrm{Pb}_{0.95} \mathrm{La}_{0.05}\left[\mathrm{Zr}_{50} \mathrm{Ti}_{45}\left(\mathrm{Mo}_{1 / 3}, \mathrm{In}_{2 / 3}\right)_{0.05}\right]_{0.9875} \mathrm{O}_{3}$ ceramics sintered at $1150^{\circ} \mathrm{C}$ exhibit good piezoelectric properties: $K_{p}$ $=0.67, Q_{m}=20$ and $T_{C}=335^{\circ} \mathrm{C}$. This means that this system is a promising candidate for the lead-free piezoelectric applications.

\section{REFERENCES}

[1] B. Jaffe, W. R. Cook and H. Jaffe, "Piezoelectric Ceramics," Academic Press, New York, 1971.

[2] S. Pilgrim, M. Audrey, E. Sutherland and E. R. Winzer, "Diffuseness as a Useful Parameter for Relaxor Ceramics," Journal of American Ceramic Society, Vol. 73, No. 
10, 1990, pp. 3122-3125. doi:10.1111/j.1151-2916.1990.tb06733.x

[3] S. Miga and K. Wojcik, "Investigation of the Diffuse Phase Transition in PLZT X/65/35 Ceramics, $X=7$ - 10," Ferroelectrics, Vol. 100, No. 1, 1989, pp. 167-173.

[4] K. L. Yadav, R. N. P. Choudhary and T. K. Chaki, "Structural, SEM and Dielectric Properties of PLZT," Journal of Materials Science, Vol. 27, No. 19, 1992, pp. 5244-5246. doi:10.1007/BF02403823

[5] G. H. Heartling, "Piezoelectric and Electrooptic Ceramics," In: R. C. Buchanan, Ed., Ceramics Materials for Electronics, Marcel Dekker, New York, 1991, pp. 139225.

[6] H. Y. Chen, X. B. Guo and Z. Y. Meng, "Processing and Properties of PMMN-PZT Quaternary Piezoelectric Ceramics for Ultrasonic Motors," Journal of Materials Chemistry and Physics, Vol. 75, No. 1-3, April 2002, pp. 202-206.

[7] P. Ari-Gur and L. Benguigui, "X-Ray Study of the PZT Solid Solutions near the Morphotropic Phase Transition," Solid State Communication, Vol. 15, No. 6, 1974, pp. 1077-1079. doi:10.1016/0038-1098(74)90535-3

[8] W. Cao and L. E. Cross, "The Ratio of Rhombohedral and Tetragonal Phases on the Morphotropic Phase Boundary in Lead Zirconate Titanate," Journal of Applied Physics, Vol. 31, 1992, pp. 1399-1402. doi:10.1143/JJAP.31.1399

[9] K. Kakegawa, J. Mohri, X. Shrasaki and K. Takahaashi, "Sluggish Pansition Between Tetragonal and Rhombohedral Phases of $\mathrm{Pb}(\mathrm{Zr}, \mathrm{Ti}) \mathrm{O}_{3}$," Journal of the American Ceramic Society, Vol. 65, October 1982, pp. 515-519. doi:10.1111/j.1151-2916.1982.tb10344.x

[10] A. V. Turik, M. F. Kupriyanov, E. N. Sidorenko and S. M.
Zaitsev, "Behavior of Piezoceramics of type $\mathrm{Pb}(\mathrm{Zr}, \mathrm{Ti}) \mathrm{O}_{3}$, near the Region of the Morphotropic Transition," Soviet Physics-Technical Physics, Vol. 25, No. 10, 1980, pp. 1251-1254.

[11] K. Kakegawa and J. Mohri, "A Compositional Fluctuation and Proporties of $\mathrm{Pb}(\mathrm{Zr}, \mathrm{Ti}) \mathrm{O}_{3}$," Solid State Communications, Vol. 24, December 1997, pp. 769-772.

[12] S. A. Mabud, "The Morphotropic Phase Boundary in PZT Solid Solution," Journal of Applied Crystallographic, Vol. 13, 1980, pp. 211-216.

[13] IEEE Standard on Piezoelectricity, IEEE Standard 1761978, Institute of Electrical and Electronic Engineers, New York, 1978.

[14] S. Kaneko, D. Z. Dong and K. Murakami, "Effect of Simultaneous Addition of $\mathrm{BiFeO}_{3}$ and $\mathrm{Ba}\left(\mathrm{Cu}_{0,5} \mathrm{~W}_{0,5}\right) \mathrm{O}_{3}$ on Lowering of Sintering Temperature of $\mathrm{Pb}(\mathrm{Zr}, \mathrm{Ti}) \mathrm{O}_{3} \mathrm{Ce}-$ ramics," Journal of the American Ceramic Society, Vol. 81, April 1998, pp. 1013-1018.

[15] B. D. Cullity, "Elements of X-Ray Diffraction," AddisonWesley Publishing Company, Inc., 1978, p. 32.

[16] A. Boutarfaia, "Investigation of Co-existence Region in Lead Zirconate Titanate Solid Solutions: X-Ray Diffraction Studies," Ceramics International, Vol. 26, No. 6, 2000, pp. 583-587. doi:10.1016/S0272-8842(99)00099-1

[17] A. Boutarfaia, "Study of Solid State Reaction and the Morphotropic Phase Boundary in $\mathrm{Pb}(\mathrm{Zr}, \mathrm{Ti}) \mathrm{O}_{3}-\mathrm{Pb}\left(\mathrm{Fe}_{1 / 5}, \mathrm{Ni}_{1 / 5}, \mathrm{Sb}_{3 / 5}\right) \mathrm{O}_{3}$ Ceramics," Ceramics International, Vol. 27, No. 1, 2001, pp. 91-97. doi:10.1016/S0272-8842(00)00047-X

[18] M. E. Lines and A. M. Glass, "Principles Application of Ferroelectric and Related Materials," Oxford University Press, Oxford, 1977. 